\title{
Sustentabilidade em áreas protegidas brasileiras: a universidade pública e o ecoturismo de conhecimento
}

\author{
Sustainability in brazilian protected areas: a public university and the \\ knowledge ecotourism \\ http://dx.doi.org/10.5007/2178-4582.2015v49n1p94 \\ José Pedro da Ros \\ Universidade Federal do Piauí, Parnaíba/PI, Brasil
}

\begin{abstract}
$\mathrm{O}$ presente artigo discute o ecoturismo em áreas protegidas e sua interface com as novas demandas do turismo relacionadas à busca de conhecimentos. Propõe-se um tipo de turismo que não limita, como geralmente acontece na prática, suas atividades à simples contemplação e consumo dos bens "naturais" ou dos bens culturais: ao contrário, o que se pretende é a interação dos ecoturistas com tais bens, em ações que envolvem o conhecer. Trata-se de um modelo de gestão de ecoturismo para as áreas protegidas brasileiras pelo Sistema Nacional de Unidades de Conservação da Natureza, com cuidados efetivos relacionados à sustentabilidade possível, protagonizada pelas comunidades locais; um modelo que se paute pela produção e socialização de conhecimentos científicos e populares, e que seja mediados, em seu desenvolvimento, por universidades públicas e instituições afins.
\end{abstract}

Palavras-chave: Ecoturismo local - Conhecimento - Áreas Protegidas - Universidades Públicas
This article discusses ecotourism in protected areas and its interface with the new demands of tourism related to the search of knowledge. We propose a type of tourism that does not limit, as usually happens in practice its activities to mere contemplation and consumption of "natural" goods or of cultural assets: on the contrary, the aim is the interaction of ecotourists with such goods through actions that involves knowledge. This is an ecotourism management model for Brazilian protected areas by the National System of Nature Conservation Units with effective care related to a possible sustainability, carried by local communities; a model that works in accordance to the production and sharing of scientific and popular knowledge, mediated, in its development, by public universities and related institutions.

Keywords: Locally based Ecotourism - Knowledge - Protected Areas - Public Universities.

\section{Palavras iniciais}

Considerando-se que na contemporaneidade há uma busca crescente, por parte do turista, a locais de visitação que proporcionem interações diretas com a "natureza", aventuras, vivências com populações de culturas singulares e, além do mais, acesso aos saberes em geral e a projetos científicos específicos ali experienciados, é que se vislumbrou o desenho propositivo de uma tipologia ecoturística, um modelo de gestão de ecoturismo de base local. Modelo com ênfase na elaboração de atividades que envolvam produção/socialização de conhecimentos científicos e populares, que seja mediado em seu desenvolvimento por universidades públicas e instituições afins, protagonizando co- 
munidades em áreas protegidas pelo Sistema Nacional de Unidades de Conservação da Natureza.

É necessário esclarecer que o presente artigo deriva de uma pesquisa de quatro anos de duração, que resultou em uma tese doutoral aprovada na Universidade de Málaga (Espanha). Será apresentada, agora e sinteticamente, uma ideia geral do trabalho, enfatizando o que se cunhou como Ecoturismo de Conhecimento.

Serão ressaltadas questões sobre a produção/socialização do conhecimento na perspectiva do Ecoturismo de Conhecimento (EC), como uma das alternativas ao turismo de massa caracterizado como predatório. As bases teóricas que sustentam as formulações presentes não se emparelham com as ideias que embasam um dado conceito específico de sociedade do conhecimento, onde a informação se diz acessível a todos, diminuindo distâncias entre as classes sociais. Esse conceito se esconde atrás de certos jargões para construir ferramentas afiadas que visam ampliar os montantes da produtividade demandada pela economia atual produzindo, isto sim, formas de exclusão em larga escala.

Também, atrás do conceito de conhecimento acima mencionado, fertilizam-se outras ideias como aquelas ligadas à sustentabilidade que, dita de modo geral, quer preservar pessoas e a "natureza" dos males da engrenagem econômica, extirpando as diferenças, a depredação, a pobreza, como se fosse possível, apenas e com simples ações sustentáveis, fazer com que isto aconteça na sociedade na qual vivemos.

Neste sentido, o Turismo não foge à regra. Multiplicam-se a cada dia, na mesma proporção que aumentam os percentuais da "indústria do turismo", empreendimentos que engrossam as fileiras de escritórios, agências e negócios economicamente compatíveis com apurados modelos excludentes da maioria da população. Os pacotes de viagens, estadias em hotéis ou ingressos para parques temáticos, museus e shows em uma, outra, e mais uma cidade são grandes, numericamente saturados e repletos de informações que escorregam pelas mentes que consomem, freneticamente, produtos e informações como o mais novo e sedutor produto de consumo. No entanto, esta não é a única maneira das pessoas se relacionarem com o seu entorno: há críticas e ações tanto quantitativa e qualitativamente que se movem em sentido contrário.

Assim, vale observar, que o perfil do turista tradicional que, contemplativo, registrava o que via acumulando informações, por exemplo, com imagens fotográficas para, posteriormente, revisitá-las como objeto de consumo, cede lugar a alguém mais dinâmico que quer registrar as suas vivências e a forma como, qualitativamente, delas participou. O "estéril" arquivo de dados vem sendo substituído por saberes onde o próprio turista também é autor dos co- 
nhecimentos produzidos/ socializados em interações com as populações as quais visita.

O ecoturismo constitui terreno fértil para isso, e pode representar uma alternativa significativa para as pessoas que buscam essas interações diretas com o meio ambiente, que é compreendido sempre na perspectiva de um ambiente social e historicamente caracterizado. Acrescenta-se aí, um sentimento de aventura que pode acompanhar o ecoturista nas vivências com culturas singulares e na troca de conhecimentos entre ambos. Há casos, também, daqueles ecoturistas que procuram ter acesso a determinados conhecimentos por meio de sua participação ativa em algumas pesquisas científicas ou mesmo em estudos e pesquisas que tenham como foco o conhecimento popular.

No presente contexto histórico, o desejado é que não se pense mais em turismo sem que esteja assentado em bases semelhantes às do ecoturismo e do que se vai chamar, neste texto, de sustentabilidade possível, por considerar suas limitações dentro da sociedade capitalista. Ou seja, mesmo que as ações sustentáveis possuam limites bem marcados pelos pilares que sustentam as relações sociais da atualidade - cujo fim último, às custas da depredação da vida, é o lucro - as ações sustentáveis aqui pretendidas tentam ser aquelas que se distanciam da "ética" do capital. Pretende-se, assim, dirigir-se por uma ética que se pauta no esforço incondicional que caminha em sentido contrário ao que fortalece a "ética" da destruição. Há que se reconhecer que, do modo de produção capitalista, resultou um acúmulo impar, em relação aos modos anteriores, de riquezas materiais e simbólicas; no entanto, e considerando as contradições que existem entre este imenso acúmulo e a imensa miserabilidade em que vive a maioria da população mundial, é que se tenta rumar numa outra direção.

Há, sem dúvida, inúmeros registros de práticas de turismo predatório das localidades visitadas em diferentes partes do mundo. Mas há, também, ações que documentam outras tendências, ou seja, aquelas que se fortalecem por estarem pautadas na compreensão de que os discursos que clamam e defendem a "sustentabilidade ambiental, social e também econômica" não podem cumprir suas promessas quando se pensa o turismo como um "fenômeno" da sociedade atual, cujas ofertas e demandas nacionais e internacionais, expressam e fundamentam as relações sociais vigentes.

Dessa forma, é necessário entender essa atividade dentro de um contexto social e histórico, pensando o turismo/ecoturismo de maneira a reconhecer nele o seu conteúdo capitalista, que se faz presente numa parte, ou seja, na forma turismo/ecoturismo para, efetivamente, perceber a complexidade do tema. Não resta o que fazer? Talvez, mas é necessário considerar os espaços 
de contradição que, se por um lado, colocam riqueza e miséria como interdependentes, por outro, colocam também o par impossibilidade/possibilidade, para buscar outras formas de pensar e fazer turismo/ecoturismo.

Nesta direção, observa-se que há um esforço dos próprios turistas, e mais especificamente dos ecoturistas, que demonstram, hoje em dia, forte interesse por atividades voltadas a uma certa perspectiva de ações "sustentáveis", dentro do que é possível, revelando comprometimento ao se sentirem implicados com as causas "ambientais" e sociais, talvez por entenderem que elas não se separam. É possível constatar este movimento pela alta demanda por viagens caracterizadas, fundamentalmente, pela busca de conhecimentos relativos à dinâmica do "meio ambiente", diferentes culturas, por exemplo, e até mesmo pela vida selvagem em excursões diferenciadas do espírito dos grandes e dispendiosos safáris.

Há que se ressaltar, também, o número significativo de acessos, pela população em geral, a informações e vídeos sobre a "natureza" em diferentes sites. Ainda, que há espaços cada vez maiores, veiculados pela mídia em programas e canais de televisão, voltados para temas ligados ao "meio ambiente" e ao ecoturismo, além de seções de viagens dos jornais, revistas de turismo cujos anúncios de pacotes ecoturísticos aumentaram significativamente nos últimos anos.

Para se refletir sobre o panorama do turismo e a forma pela qual se expressam as forças da economia capitalista, torna-se interessante conhecer algumas informações consistentes sobre a real situação da sociedade, cujas determinações des-orientam o turismo em suas especificidades. Basta "cruzar" alguns dados com a realidade do turismo para que se constate por que ele é privilégio de poucos e por que ele depreda.

Segundo a Organização Mundial do Turismo (OMT, 2010), o crescimento dessa atividade apresentará uma taxa de $4,1 \%$ até 2020 . Afirmam, ainda, que o segmento receptivo do turismo está crescendo a um ritmo anual de $11,2 \%$, o que representa o dobro do crescimento da atividade econômica mundial. Porém, é conveniente chamar a atenção para o fato de que as chances de usufruir do turismo/lazer, educação de qualidade ou dos direitos à saúde, por exemplo, cabem, somente, a poucos e não à maioria da população.

Outro fato importante a ser pontuado é que, além de excludente, o turismo pode ser visto também uma "faca de dois gumes", principalmente se considerarmos o ritmo acelerado desse crescimento. Ou seja, dentro da própria atividade turística há uma dualidade, uma vez que os impactos dela decorrentes podem ser, e frequentemente o são, extremamente negativos, já que interferem qualitativamente na vida dos autóctones e dos locais considerados 
como turísticos. Existem, também neste sentido, diversas metáforas possíveis para ilustrar esta constatação, como por exemplo, "o turismo é como o fogo, serve para trazer conforto, mas pode incendiar o local".

$\mathrm{Na}$ opinião de Swarbrooke (2000), há vários fatores que determinam o resultado dos impactos socioculturais, tanto os positivos como os negativos. Dentre eles: a força e a coerência da sociedade e da cultura locais; a natureza do turismo na localidade; o grau de desenvolvimento social e econômico da população local em relação aos turistas; as medidas tomadas pelo setor público para administrar o turismo de modo a minimizar os impactos socioculturais.

No entanto, o autor pontua questões que parecem desconsiderar a realidade da sociedade contemporânea na qual, por exemplo, o "grau de desenvolvimento" entre visitantes e visitados não é o que explica os custos/impactos citados. E não será a sustentabilidade, dita de forma geral sem ser qualificada, que apontará outros rumos ao turismo como atividade de espantosa expansão.

Considerando que o lócus da proposição aqui apresentada é o ecoturismo nas áreas protegidas - chamadas no Brasil de Unidades de Conservação (UC) - é expressivo informar que, na atualidade, o número e extensão dessas áreas em todo o planeta têm crescido de forma significativa: cobrem 18,8 milhões de quilômetros quadrados, o que equivale a $12,56 \%$ da superfície terrestre (AGÊNCIA ESTADO, 2003). No entanto, essas áreas, que em sua grande maioria são públicas, contam com inexpressivos investimentos. Isso acarreta uma busca por outras fontes de financiamento para as iniciativas relacionadas ao ecoturismo, mesmo sendo esta a única possibilidade/segmento de turismo na maioria dessas áreas e despontando-se com uma notável alternativa voltada a uma efetiva ou possível sustentabilidade. Ainda, deve-se lembrar, como se afirmou acima, que tal perspectiva tem grandes limites na sociedade atual.

A atividade turística como um todo pode constituir bases para alavancar a economia dos lugares atingindo a vida pessoal e social dos sujeitos que ali vivem. Não se quer com isto supervalorizar a atividade turística colocando sobre ela responsabilidades que transcendem o seu escopo. Mas também não se pode esquecer que a troca provocada pelo contato entre culturas distintas tenha que ser cuidadosamente pensada e acompanhada, uma vez que essa troca pode dar margem a problemas sérios como importação acrítica de valores, padronizações negativas, discriminações de toda a ordem, ou algo como a retratada exploração de menores encontrada em larga escala em alguns destinos do turismo de massa do Brasil. Deseja-se apenas destacar as potencialidades do turismo como forma de melhoria de qualidade de vida, mesmo que enquadrada dentro das im-possibilidades do capitalismo, principalmente em locais onde a população se vê mais atingida pelas dificuldades pelas quais passa a economia mundial. 
Nesse sentido, e associada à exuberância de certos locais e de sua população, a atividade turística, se planejada e gerenciada dentro do que se quer chamar de sustentabilidade possível, pode trazer benefícios tanto ao "meio ambiente" como às pessoas da localidade, em termos de geração de emprego (não confundir com subemprego); pode também trazer contribuições para economia local, desde que voltada inteiramente às prioridades apontadas pela própria população e administrada num sistema coletivo de gerenciamento através, por exemplo, de associações ou cooperativas, por meio das quais a população local protagoniza os produtos turísticos a serem formatados.

Há um efeito multiplicador dos gastos dos turistas na geração de receitas. Verbas que, inclusive, podem ser investidas na recuperação de áreas já depredadas, na prevenção de agressões ao "ambiente físico" e cultural ou mesmo em pesquisas científicas aplicadas às áreas protegidas em questão e relacionadas a estas perspectivas apontadas pelo EC. Perspectivas que podem proporcionar ao visitante o sentimento da aventura de conhecer, a possibilidade de se inteirar e participar de pesquisas e estudos realizados nas UC; ou, ainda, de vivenciar práticas culturais e ter acesso às sabedorias populares, compartilhando aquelas que possui, além de desfrutar do "meio ambiente" e hospitalidade local. Em outras palavras, práticas turísticas que por sua vez, possam efetivamente ser transformadoras, dentro do possível nesta sociedade, da realidade das áreas protegidas brasileiras, das populações dos arredores das mesmas e de certas formas de turismo tais como se desenvolvem em alguns locais do Brasil. .

No que se refere à sustentabilidade possível (mesmo que presa aos grilhões do capitalismo) e sua relação com o turismo, o que se propõe é o ecoturismo e sua interface com o conhecimento, já que esta interface possui força enquanto atividade turística, ou seja, a busca de conhecimento passa a se constituir como uma grande motivação para o visitante. $\mathrm{O}$ EC aqui proposto não prescindirá de recursos financeiros e investimentos, públicos ou privados, e fará esforços para ampliar a participação das comunidades locais na produção de renda visando melhores condições de vida (ainda que no limite demarcado pela dinâmica da sociedade).

A qualidade de vida não se restringe somente ao aumento dessa renda, mas relaciona-se à participação e reconhecimento que a própria comunidade tem de si como produtora/socializadora de seus saberes. Enquanto conjunto de pessoas organizadas, a comunidade também se apropria criticamente dos conhecimentos trazidos e veiculados por pesquisadores, estudantes e turistas que procuram, de diferentes maneiras e em diferentes níveis, as propostas dessa modalidade de ecoturismo. 


\section{Sustentabilidade, Ecoturismo e as Universidades Públicas.}

De forma sintética, é importante ressaltar alguns pontos chave que permeiam a teoria do ecoturismo e que são imprescindíveis para sua compreensão em relação à sustentabilidade. Sabe-se que há dificuldades próprias da sociedade atual em conciliar interesses econômicos com preocupações ecológicas e sociais. Isto talvez constitua o cerne da polêmica que se acentua, mais ainda, quando se questiona se a sustentabilidade pode ou não, ser possível no capitalismo. Sobre este tema, Carneiro e Faria (2001, p. 19) em Sustentabilidade Ecológica no Turismo, confirmam: "O antagonismo entre sustentabilidade e crescimento econômico é próprio da sociedade capitalista"

No diálogo do turismo com sustentabilidade criou-se um termo denominado Turismo Sustentável (TS) que, para ser considerado em sintonia com o ecoturismo deve estar pautado nas premissas do que se cunhou, aqui, como sustentabilidade possível; ou seja, com um horizonte de longo prazo, e passos seguros firmados no respeito às gerações futuras.

O entendimento do Ministério do Turismo (MTur) sobre o segmento ecoturismo não o desvincula da perspectiva da "sustentabilidade": "Ecoturismo pode ser entendido como as atividades turísticas baseadas na relação sustentável com a natureza, comprometidas com a conservação e a educação ambiental" (BRASIL, 2006, p.11). Se, de acordo com o MTur, a sustentabilidade é premissa para o turismo em qualquer destino - sendo esta, sem dúvida, uma importante questão às políticas públicas no que se refere a difícil sustentabilidade do turismo - fica a reflexão sobre o que realmente é ecoturismo se concebido não apenas pelo viés da sustentabilidade cuja preocupação é sustentar as condições básicas para a reprodução do capital.

O Ministério do Turismo (MTur),afirma ainda que:

Ecoturismo é um segmento da atividade turística que utiliza, de forma sustentável, o patrimônio natural e cultural, incentiva sua conservação e busca a formação de uma consciência ambientalista através da interpretação do ambiente, promovendo o bem -estar das populações envolvidas (BRASIL - MTUR, 2006).

[...] Caracteriza-se pelo contato com ambientes naturais e pela realização de atividades que possam proporcionar a vivência e o conhecimento da natureza, e pela proteção das áreas onde ocorre. Ou seja, assenta-se sobre o tripé interpretação, conservação e sustentabilidade (BRASIL, 2006, p. 11).

Enfatiza-se, assim, a importância de caracterizar de maneira mais precisa o termo sustentabilidade, pois sua utilização como conceito amplo pode dar 
margem a interpretações equivocadas, pasteurizando os diferentes interesses da sociedade atual. É por este motivo que a ele se acrescenta, sempre, o termo possível.

O conceito de EC como tipologia turística contempla o desenvolvimento de atividades, a interação entre os ecoturistas e a população local, mediado, como já se disse, pela produção/socialização de conhecimentos científicos e populares. Esse conceito difere num ponto específico de diversos atrativos turísticos encontrados em outras tipologias, tais como a do turismo científico, a do cultural, a do turismo de aventura. Em outras palavras, exige, imprescindivelmente, o envolvimento da população local e o intercâmbio incondicional de saberes. Desta maneira, todos/todas são sujeitos de um processo em que a diversidade os constitui e por eles é constituída.

As parcerias com as universidades próximas aos locais potencialmente turísticos, neste contexto de produção e socialização de conhecimento podem ser de grande importância, cabendo às instituições o gerenciamento dos projetos, integrando o ensino, a pesquisa e a extensão, bem como a promoção de iniciativas que, interdisciplinarmente, congreguem professores e alunos de diversos cursos. Além das universidades, outros órgãos públicos podem ser bem-vindos.

Desde os primórdios do ecoturismo, a divulgação de conhecimentos significativos tem sido utilizada e apresentada aos turistas para agregar valor aos destinos e atividades do ecoturismo, principalmente como ferramenta sensibilizadora para educação "ambiental". Associado às universidades, poderá haver um maior aprofundamento da relação possível entre as diferentes formas de divulgação de conhecimentos e a formatação de ações relacionadas ao EC, especificamente, para que visitantes interajam mais com as potencialidades locais. Consequentemente, ficarão mais satisfeitos com as aprendizagens realizadas e com aquilo que puderam ensinar. Esse processo traz benefícios para o ecoturista, para as pesquisas e para a comunidade que se envolve ativamente nessas atividades, ensinando e aprendendo. A participação das instituições de ensino superior é, neste sentido, um diferencial significativo na proposta.

Portanto, o EC, necessariamente:

- respeita as premissas do aqui considerado "autêntico ecoturismo", descrito anteriormente, com vistas a sustentabilidade possível, valorizando o "meio ambiente" como patrimônio social; com foco nos considerados pilares que alicerçam a sustentabilidade no turismo: econômico/ambiental/social;

- é desenvolvido com base local, isto é, pela e com a comunidade local que protagoniza o ecoturismo da sua região, com retorno financeiro inteiramente voltado aos fins das próprias iniciativas do chamado EC; 
- é mediado, em seu desenvolvimento e gestão, pelos cursos superiores de turismo de universidades públicas, com possíveis parcerias com outras áreas na perspectiva da interdisciplinaridade, da pesquisa e extensão; poderá contar também com possíveis ações, apoios/vínculos de outras instituições de cunho público;

- é Situado em Unidades de Conservação da Natureza (SNUC) nacionais e/ou em seus arredores;

- tem como ênfase a interação/produção/socialização entre os conhecimentos científico e o popular; e, em relação à diversificação da oferta de serviços, pode associar-se a atividades comuns a outras tipologias de turismo, como o "eco"- turismo de aventura, o "eco"- turismo científico e "eco" - turismo cultural.

As áreas protegidas brasileiras, formadas por mais de 1 milhão de $\mathrm{km}^{2}$ sob forma de Unidades de Conservação (UCs), caracterizam-se como de expressiva potencialidade para o desenvolvimento do ecoturismo associado a ações que objetivam uma sustentabilidade possível, ou seja, aquela que pode ser almejada dentro dos limites que a sociedade atual possui.

Considerando a realidade das UCs do Brasil, que clamam por esforços destinados à conservação da "natureza", justifica-se ainda mais a proposta de contar com ações de instituições públicas tendo em vista o quadro de subdesenvolvimento das comunidades de entorno destas UCs. Assim as Universidades e outras instituições Públicas podem (e devem) ter um papel que muitas vezes transcende o escopo do que se propõe, contribuindo expressivamente para a transformação dessa realidade.

A singularidade da vegetação, dos recursos hídricos, da geografia, aliada à existência de significativos projetos científicos com potencialidade para atrair visitação turística - como a hospitalidade, a gastronomia e o "exotismo" de culturas tradicionais e dos saberes populares presentes nas UCs brasileiras - contribuem para o expressivo potencial do EC. Além disso, a economia movimentada por esse tipo específico de turismo, guardados seus princípios fundamentais, pode tornar-se uma alternativa para a melhoria da qualidade de vida das comunidades locais; entenda-se: promoção de IDH.

Como se observa, as possibilidades de colaboração participativa entre Universidades Públicas e projetos relacionados ao EC podem ser transformadoras de uma parte significativa da realidade destas localidades, mesmo no contexto excludente do capitalismo. As iniciativas de ecoturismo, que tenham como foco o conhecimento interdisciplinar desejado por este ramo das ciências sociais, podem favorecer o fortalecimento de elos necessários entre o ensino, a pesquisa e a extensão, tão importantes às Instituições de ensino superior públicas. 
As próprias instituições públicas encabeçariam atividades relacionadas ao EC no que diz respeito à captação de recursos para enriquecer as ações de extensão com o intercâmbio entre os estudantes e turistas nacionais e estrangeiros no que se refere à ampliação de vivências e estudos dos acadêmicos. Segundo Rauber (2010, p. 12057), “a extensão universitária pressupõe uma ação junto à comunidade, disponibilizando ao público externo o conhecimento adquirido com o ensino e a pesquisa que foram desenvolvidos pela instituição". Além do mais, a participação do "ecoturista de conhecimento" resultaria em ganhos relacionados à formação de sujeitos defensores de um turismo não predatório, à divulgação das riquezas físicas e simbólicas dos lugares onde se realizam tais atividades e ao alcance dos objetivos das próprias universidades.

A parceria dos cursos de turismo das universidades públicas com cursos de outras áreas como, por exemplo, a biologia, botânica, arqueologia, geologia, agronomia, engenharias, entre outros, caracterizaria outra forma de pensar o turismo e, principalmente, de ampliar, na perspectiva da interdisciplinarmente, as possibilidades de ações dos futuros profissionais em seus trabalhos de campo. Dessa maneira, os programas de extensão universitária podem demonstrar a importância de sua existência na relação estabelecida entre instituição e sociedade. Essa aproximação é também uma das maneiras de trocar conhecimentos e experiências entre professores, alunos e população, por meio de processos de ensino e aprendizagem com base nas práticas cotidianas, buscando o envolvimento do máximo de alunos, pois, segundo Rauber (2010), a aprendizagem só acontece quando a teoria é aplicada na prática.

Assim, o desenvolvimento de projetos de EC articulados pelo curso de turismo e implementados em áreas protegidas, em parceria com a comunidade local e apoio efetivo da universidade pública, abre possibilidades para uma formação cientificamente interdisciplinar, por meio de parcerias com outros departamentos/cursos. Além disso, as pesquisas de campo em áreas protegidas podem também vir a auxiliar na elaboração de um produto turístico sustentável. Vale destacar que o manancial de possibilidades turísticas de algumas regiões é grande, e o desenvolvimento do EC pode constituir-se como alternativa significativa e organizadora de um eixo temático que congregue diferentes cursos numa mesma atividade acadêmica de cunho interdisciplinar. Sem essa dúvida, essas parcerias contribuiriam para reduzir a distância entre os diferentes campos do conhecimento, cartesianamente apartados.

Neste sentido, de acordo com as ideias de Mészáros (2006) o conhecimento científico deve ser orientado para as comunidades mais isoladas territorialmente, principalmente se tratar de pessoas empobrecidas financeiramente que vivem à margem da sociedade atual e distantes das facilidades das grandes cidades. Estabelecer um diálogo com o saber popular, em busca de democrati- 
zação do conhecimento, articulando-o com o conhecimento científico, deveria ser primordial na atuação das universidades.

Destas iniciativas poderiam nascer novos projetos pedagógicos, delineamento de ações no interior do campus universitário e fora dele, além de publicação de artigos conjuntos que integrem, simultaneamente, particularidades de diversos cursos. O trabalho interdisciplinar, associado ao modelo de vida universitária mais integrada, constitui possibilidades riquíssimas para o EC, dentro de uma dinâmica de flexibilidade e de considerações à realidade social na qual os seres humanos protagonizam a história da vida, sem muitas vezes, gozar do direito a usufruir, irrestritamente, de todas as suas riquezas. Tais projetos, pelas razões acima incluídas, não pretendem adquirir caráter salvacionista; o que se pretende é dizer não às leis predatórias do humano.

\section{Palavras finais}

O turismo é produto do capitalismo quando as viagens, os monumentos, as paisagens, os povos "exóticos", transformam-se em bens de consumo, em mercadorias, fenômeno que aconteceu, notadamente, após os anos 50 do século passado (OURIQUES, 2005). Como mercadoria, passaram a ser categorizados como coisa, de tal forma que, coisificados, desistoricizados, justamente por este motivo, transformaram-se em bens de troca por alguma quantidade de dinheiro. A chave do consumo parece, assim, adquirir vida no turismo: a troca e produção de dividendos acontecem sem considerar se o lazer ou conhecer são realmente lazer e conhecer, e se há vida de seres humanos neles implicados. Assim, comunidades que habitam locais turísticos prejudicam-se e não têm como desfrutar do possível benefício advindo do turismo em sua região.

O vai e vem de parcelas da população que se deslocam dentro de seus próprios países e, crescentemente, nos últimos tempos para o exterior, é considerado, muitas vezes, como lazer/conhecer que não poluem, ou seja, quase um "ecolazer" promovido pela atividade turística. vista como neutra frente aos estragos do meio ambiente hominizado, sem considerar que este ambiente supõe encontro de sujeitos que interagem socialmente. Tal neutralidade, própria do modo de pensar da modernidade, se assenta na racionalidade científica que separa os seres humanos, com seus conhecimentos, cultura e saberes, do chamado meio ambiente natural. Infelizmente, muitos autores da área do turismo - alguns deles citados neste texto - não consideram questões como estas em suas teorizações sobre a atividade turística, inclusive aqueles que se dizem adeptos da perspectiva salvadora da sustentabilidade, da geração de empregos e outros "bens" que o turismo pode fazer. 
Mencionou-se que o ecoturismo pode vir a gerar emprego, possibilitando a melhoria da renda de populações locais, mas os mesmos cuidados que se deve ter com as questões acima assinaladas, deve-se ter com esta: gerar empregos, implementar um mercado de trabalho pode levar, apenas, ao que acontece em toda a sociedade do trabalho: baixos salários, subemprego, exploração, exclusão. Daí, falar-se tanto e esforçar-se tanto na defesa de um ecoturismo que, contraditoriamente aos mandos da sociedade atual, aponte para possíveis atitudes de resistência. Daí, pensar-se em alternativas para o desenvolvimento do ecoturismo nas áreas protegidas, praticado em parceria com instituições públicas, protagonizado pela população local dos destinos turísticos, que passariam a ser vistos e valorizados não como simples destinos (concepção corrente) ou como totalmente regidos por destinos alheio às suas vidas.

A propósito, de acordo com Ouriques (2005), o termo destino já aponta para esta visão de turismo gerido pelas formas de comercialização do mercado dos tempos posteriores à segunda grande guerra: destino do lucro, tanto frente aos considerados marcos dos grandes feitos, das obras arquitetônicas, de certas obras de arte ou o das comunidades periféricas, empobrecidas, "exoticizadas" por uma dada visão da cultura dominante. No último caso, vale ressaltar, que as "leis" deste tipo de relação com estes povos são tão fortes que olhadores e olhados tornam-se cúmplices de uma mesma empreitada: a de coisificar e coisificar-se, marginalizando o humano, ao colocar no pódio a mercadoria compreendida como coisa que atende as necessidades do mercado, não importando se satisfaça as necessidades de homens e mulheres na sociedade em que vivem (MARX, 1984).

Também nos grandes centros urbanos, reproduz-se esta dinâmica: as praças, as avenidas arborizadas, as fachadas das lojas que exibem vitrines sedutoras, os restaurantes típicos, os cafés, parecem viver por si, sem que precisem de pessoas à sua volta e em seus alicerces. Uma vez que tudo e todos estão desistoricizados compõem, apenas um destino onde se compra a imagem do lugar ou a imagem daquele velhinho, típico da cidade, sentado no banco (rústico e de madeira também típica) de um jardim florido, lendo seu jornal. A "romanticidade" da cena se coisifica ao se tornar objeto de sucessivas degustações do típico fotografado, onde banco, velhinho, jardim equivalem-se pela tipicidade da região do destino turístico. E, é neste contexto que se proliferam os discursos da sustentabilidade.

É por este motivo que, quando se fala em sustentabilidade possível ou responsável, ou quando se fala em ecoturismo autêntico, não se desconhecem as insustentabilidades de ações que pretendem garantir vida digna a todos, neste momento histórico. Isto seria utopia na sociedade atual; não porque, individualmente, não seja algo fortemente pretendido, mas porque possivelmente não 
"caiba" dentro da ótica capitalista. Sustentabilidade e ecoturismo aqui adjetivados com estas qualidades, associam-se àquilo que, de forma contraditória se possa, talvez, fazer.

A perspectiva do EC não se emparelha com aquelas que justificam seus fazeres na política do ecologicamente correto. Quem sabe, como filosofia de base, que serve para esconder o desrespeito que a sociedade em geral pratica e precisa praticar para manter-se capitalista: respeito ao 'meio ambiente'. Esquece-se que não existe a tal "natureza/ambiente natural”, porque é social e, como tal, ao erguer-se na e pela exploração de seus sujeitos, não pode desvencilhar-se inteiramente do desrespeito. Se são erguidas bandeiras que clamam por vida digna é porque a indignidade se propaga, majestosamente, entre populações inteiras. O prefixo eco, por ele mesmo, não mudará essa realidade, por mais bem intencionados que estejam os defensores do ecologismo.

O EC, nos espaços viabilizados pelas contradições do capital, pretende dizer não a este estado de degradação, propondo uma alternativa em que se possa "respirar outros ares" (ainda que a poluição dos ares se constitua como algo da totalidade da sociedade). Não pretende defender um desenvolvimento com sustentabilidade, definida dentro de uma generalidade, na qual cabem todos os engodos do turismo redentor. $\mathrm{O}$ ecoturismo precisa ser compreendido como parte do todo social e que se faz forma como turismo banhado pelos conteúdos deste social.

Mesmo com uma necessária dose de clareza quanto ao significado da relação turismo e consumo levanta-se uma questão importante: o conhecimento, no caso da proposta de ecoturismo aqui defendida, não se constitui como mercadoria? Corre-se todos os riscos de que isto seja verdade, pois, afinal, marchamos nas trilhas adubadas por estes mesmos riscos. Traçar caminhos que não conduzam somente a eles é o desejo maior. O sim e o não (a afirmação ou a negação) possuem as mesmas chances de se realizarem, mesmo que se considere que o adubo esteja, em maior quantidade, na afirmação. Resta o esforço que, orientado pelas memórias de futuro (BAKHTIN, 2003), ajuda a sonhar com a superação do que está posto como status quo.

Cunhou-se e caracterizou-se uma nova tipologia denominada de Ecoturismo de Conhecimento mesmo considerando que a alternativa de seccionamento da atividade turística não seja a mais indicada para se repensar o turismo como um todo. Quanto ao potencial desta nova tipologia, pode-se dizer que as alternativas ecoturísticas consonantes àquilo que foi formulado, associadas às riquezas "naturais" e culturais expressivas de todas as áreas protegidas brasileiras, são fortemente significativas para o êxito da atividade, principalmente pelo fato de atenderem as demandas atuais (nacionais e internacionais) do ecoturismo e, também, por preverem a participação interdisciplinar de profes- 
sores e estudantes de universidades públicas (integrando diversos cursos com o curso de turismo), e de instituições públicas afins.

Outro ponto significativo a ser destacado como potencializador dessa proposta é o de que as comunidades protagonizem o turismo, participando no planejamento e execução dos projetos de estudos e pesquisas em andamento ou a serem desenvolvidos nos locais eleitos para a realização do EC; ou seja, aqueles que já possuem projetos científicos passíveis de interação com os saberes populares locais ou que poderão ser criados com estas características. A criação de novos empregos e a extensão de projetos educacionais para todos podem melhorar o IDH das populações, mesmo que isto signifique apenas um paliativo à condição de extrema exclusão na qual vive parte significativa da população brasileira que, no caso, geralmente habita as imediações das áreas protegidas.

Considerando o exposto, é necessário, também, pensar que em tais iniciativas o visitante não é apenas um contemplador. Participará de forma ativa e comprometida das ações realizadas, podendo contribuir com alguns rumos do que acontece nos locais, na medida em que seus conhecimentos e bagagem de experiências sejam valorizados da mesma forma que as de outros integrantes dos projetos. A participação em uma pesquisa determinada modificará as atividades de interação do visitante com a produção e socialização do conhecimento. Além disto, vale considerar que mesmo que a viagem tenha como motivação principal a pesquisa científica ou o conhecimento popular, interessará mais ainda aos visitantes se puderem, também, desfrutar de outras opções de lazer como passeios na região, contemplação das belezas ditas naturais, o sol e as praias presentes, vivências culturais, festas regionais, atividades de aventura desenvolvidas na região, entre outros.

Ainda é precipitado perspectivar algo concreto para tal. O que aqui se apresentou, representa o desenho de um primeiro passo, mas é certo que outros estudos se farão necessários. Avaliações sucessivas constantes falarão da viabilidade desta proposta e dos ajustes que a prática e a perspectiva teórica que a embasa demandarão. As considerações acima expostas não constituem um fechamento; são finais, apenas, temporariamente.

No que se refere à forte inclinação pela busca da pretendida sustentabilidade tão falada nos dias de hoje, grifada neste texto como sustentabilidade possível, é importante frisar que, mesmo considerando as (im)possibilidades desta intenção, o EC envida esforços nesta direção.

\section{Referências}

AGÊNCIA ESTADO. Relatório mostra situação dos Parques do mundo. O Estado de São Paulo, 09 de setembro de 2003. Disponível em http://ciencia.estadao.com.br/noticias/geral,relatorio-mostra-situacao-dos-parques-do-mundo,20030909p73480 Acesso em: 09 dez. 2014. 
ROS, José Pedro Da. Sustentabilidade em áreas protegidas brasileiras: a universidade pública e o...

BAKHTIN, M. Estética da criação verbal. 4. ed. Tradução de Paulo Bezerra. São Paulo: Martins Fontes, 2003.

BAPTISTA, Luciene Cristina Imes. Epistemologia do Turismo: o materialismo histórico dialético como metodologia de pesquisa social. Londrina, 35 p. Trabalho de Conclusão de Curso (Graduação em Turismo com ênfase em Hotelaria) - Centro de Ciências Empresariais e Sociais Aplicadas, Universidade Norte do Paraná, Londrina, 2010.

BRASIL (Ministério do Turismo). Plano Nacional do Turismo: Diretrizes, Metas e Programas. 2003-2007. Brasília, DF, 29 abr. 2003. Disponível em: http://www.turismo.gov.br/export/ sites/default/turismo/o ministerio/publicacoes/downloads publicacoes/plano nacional turismo 2003 2007.pdf Acesso em: 10 jan. 2012.

. (Ministério do Turismo). Segmentação do Turismo: marcos conceituais. Brasília, 2006. Disponível em: http://www.turismo.gov.br/export/sites/default/turismo/o ministerio/publicacoes/downloads_publicacoes/Marcos_Conceituais.pdf Acesso em: 14 jan. 2012.

BRASIL. Constituição (1988). Constituição da República Federativa do Brasil de 1988. Brasília, 5 de outubro de 1988. Disponível em: http://www.planalto.gov.br/ccivil_03/constituicao/ constituicao.htm Acesso em: 15 jan. 2012.

CARNEIRO, Kátia Saraiva; FARIA, Dóris Santos. Sustentabilidade ecológica no turismo. Brasília: UnB, 2001.

KRIPENDORF, Jost. Sociologia do turismo: para uma nova compreensão do lazer e das viagens. São Paulo: Aleph, 2001.

OMT (WTO) - ORGANIZAÇÃO MUNDIAL DE TURISMO. Dados sobre a atividade turística. Disponível em http://statistics.unwto.org/es Acesso em maio de 2010

OURIQUES, Helton Ricardo. A produção do turismo: fetichismo e dependência. Campinas SP: Ed. Alínea, 2005.

MARX, Karl. O Capital. Livro 1, Vol. I., $9^{\text {a }}$ ed., Trad. Reginaldo Sant'Anna. São Paulo: Difel, 1984.

MÉSZÁROS, István. Educação para além do capital. São Paulo, Campinas: Boitempo, 2006.

RAUBER, Suliane Beatriz. Extensão universitária e formação profissional: indissociáveis no processo de aprendizagem da Universidade Católica de Brasília - UCB. Disponível em: http:// www.pucpr.br/eventos/educere/educere2008/anais/pdf/792 883.pdf Acesso em: jan. 2010.

SACHS, Ignacy. Estratégias de Transição para o Século XXI. In: BURSZTYN, Marcel (Org). Para Pensar o Desenvolvimento Sustentável. São Paulo, Brasiliense, 1993.

SWARBROOKE, John. Turismo Sustentável. São Paulo: Editora Aleph, 2000.

WORLDWATCH INSTITUTE. Relatório Estado do mundo 2010. Transformando Culturas: do consumismo à sustentabilidade. Relatório do Worldwatch Institute sobre o Avanço Rumo a uma Sociedade Sustentável. Salvador, BA: UMA - Universidade Livre da Mata Atlântica, 2010. Disponível em: <http://www.wwiuma.org.br/estado_2010.pdf > Acesso em: 10 ago. 2010. 
Submissão em: 16/11/2014

Revisado em 21/122014

Aceito em 21/12/2014

José Pedro Da Ros é Doutor em Gestión y Desarrollo Turístico Sostenible pela Universidade de Málaga (UMA), título reconhecido pelo Programa de Pós Graduação em Desenvolvimento e Meio Ambiente PRODEMA da Universidade Federal do Ceará, UFC. Mestre em Mídia e Conhecimento, UFSC. Especialista em Ecoturismo: interpretação e planejamento de atividades naturais, UFLA. Bacharel em Turismo, ASSESC - Professor Adjunto do Curso Superior de Bacharelado em Turismo da UFPI - Campus Parnaíba. Endereço para correspondência: Universidade Federal do Piauí UFPI - Campus Ministro Reis Velloso / Parnaíba - Avenida São Sebastião, 2819. CEP 64202 -020. Parnaíba/PI. Email: zdaros@gmail.com 